\title{
Sınıf Öğretmenlerinin Beslenme Alışkanlıklarının İncelenmesi
}

\author{
DOI: 10.26466/opus.573261 \\ * \\ Eyüp Bozkurt* - Ramazan Erdoğan** \\ * Dr. Öğr. Üyesi, Frrat Üniversitesi, Eğitim Fakültesi, Elazı̆̆ / Türkiye \\ E-Posta: ebozkurt@firat.edu.tr \\ ORCID: 0000-0001-8009-3478 \\ ** Gençlik ve Spor İl Müdürlüğü, Elazığ/ Türkiye \\ E-Posta: ramaznerdogan@hotmail.com \\ ORCID: $\underline{0000-0001-5337-942 X}$
}

\section{Öz}

Sınıf öğretmenleri hitap ettiği kitle göz önüne alındı̆̆ında öğrencilere rol model olacak ve kazandikları alışkanlıklara katkı sunacak bir meslek alanıdır. Bu bă̆lamda sını öğretmenlerinin beslenme alışkanlıkları da önemli bir yer tutmaktadır. Çünkü öğretmenler doğru ve düzenli bir beslenme alışkanlı̆̆ına sahip olursa öğrencilerine de bu alışkanlığı kazandırabilir. Bu çalışmada sınıföğretmenlerinin beslenme alışkanlıklarının incelenmesi amaçlanmıştır. Bu amaç doğrultusunda hazırlanmış olan beslenme alışkanlığı anketi sınıf öğretmenlerine uygulanmıştır. Verilerin analizinde SPSS paket programı kullanılarak, yüzde, frekans, standart sapma ve aritmetik ortalama testleri uygulanmıştır. Araştırma sonuçlarına göre öğretmenlerin büyük bir çoğunluğu beslenme eğitimi almadıklarını, sigara ve alkol alışkanlığının olmadığını, herhangi bir fiziksel aktivite yapmadığııı ifade etmişlerdir. Araştırmaya katılan ö̆̆retmenlerin yarısına yakını kahvaltı alışkanlığının olmadığını ve öğün atladığını, en çok atladıkları öğ̈̈̈nün ise öğle yemeği olduğunu belirtmişlerdir. Öğretmenler öğün atlama nedeni olarak ta firsat bulamadıkları için öğün atlattıklarım ifade etmişlerdir. Araştırmaya katılan öğretmenlerin büyük bir çoğunluğu günde iki litreden az su tükettiklerini ve günde beş ve altı bardaktan daha az çay kahve tükettiklerini ifade etmişlerdir. Yapılan araştırma sonucunda öğretmenlerin beslenme alı̧̧kanlıklarının ve bilgi düzeylerinin yetersiz olduğu görülmektedir.

Anahtar Kelimeler: Beslenme, Beslenme ve Öğretmen, Beslenme Alışkanlı̆̆ı 


\title{
Investigation of the Nutritional Habits of Classroom Teachers
}

$*$

\begin{abstract}
Classroom teaching, considering the population they address, is a field of profession that constitutes a role model for students and contributes to the habits they adopt. In this sense, the nutritional habits of classroom teachers also constitute a significant point. This is because, when teachers have a correct and regular nutritional habit, they can instill this habit in students. In this study, it was aimed to investigate the nutritional habits of classroom teachers. The nutritional habit survey, prepared in line with this aim, was conducted with classroom teachers. In the data analysis, SPSS package software was used and percentage, frequency, standard deviation and arithmetic mean tests were conducted. According to the results of the study, a majority of the teachers stated that they did not receive nutritional training, did not have smoking or drinking habits in addition to not doing any physical activity. Approximately half of the participating teachers in the study reported that they do not have a habit of having breakfast and they skipped meals as well as reporting that the most skipped meal was the lunch. The teachers, as the reason for skipping meals, stated that they skipped meals because they could not get the chance. A majority of the participating teachers in the study also stated that they consumed less than two liters of waters in a day and they consumed less than five or six cups of tea or coffee in a day. As a result of the study, it was observed that the nutritional habits of teachers and the level of their knowledge were insufficient.
\end{abstract}

Keywords: Nutrition, Nutrition and Teacher, Nutritional Habit 


\section{Giriş}

Günümüzde dünya çapında insanların yaşam tarzı ve beslenme alışkanlıklarında önceki yüzyıllara göre önemli değişiklikler olmuştur (Di Daniele N, 2019). Bu değişikliklerin yanı sıra gelişen teknoloji ve hareketsiz yaşam tarzı bireylerin fiziksel uygunluklarını koruması ve sağlıklı bir yaşam sürdürebilmesi için düzenli olarak yapılan fiziksel aktiviteyle beraber yeterli ve dengeli beslenme alışkanlıklarını yaşamlarının tüm dönemlerinde önemli bir hale getirmiştir. (Güleç ve ark., 2008; T.C Sağlık Bakanlığ Türkiye Halk Sağlığı Kurumu, 2016).

Sağlıklı bir yaşamın sürdürebilmesi toplumun her kesimi için önemli olduğu kadar eğitim çalışanları açısından da önemlidir. Eğitim çalışanlarının gelişen teknolojinin yanı sıra hareketsiz yaşam tarzlarıda göz önünde bulundurularak yaşamlarını sağlıklı bir şekilde devam ettirebilmesi için aileden başlanarak yeterli ve dengeli beslenmeleri ve kazanılan bu beslenme alışkanlıklarını yaşam biçimi haline getirmeleriyle mümkün olacaktır (Sabbağ ve Sürücüoğlu, 2011; Merdol, 2008). Beslenme, insanın büyüme, gelişme, daha zinde ve üretken olarak yaşamanı devam ettirebilmesi için besin öğelerini yeteri kadar alıp vücutta kullanmasıdır (Küçük, 2019; Saygin ve ark., 2011).

Yeterli ve dengeli beslenme ise; insanların yaşamlarını sağlıklı bir biçimde sürdürebilmesi için tüm besin öğelerinden yeterli ve gerekli miktarda alınması vücutta kullanılmasıdır. Sağlıklı, yeterli ve dengeli beslenme fiziksel uygunluk, sağlık ve hastalıklara yakalanma riskinden korunmak için önemlidir (Demirezen ve Coşansu, 2005; Mukudi, 2003). Yalnızca besine ulaşabilmek veya satın almak değil beslenme bilgisi sağlıklı ve en doğru besin öğesi seçimlerimde önemlidir. Yetersiz ya da yanlış beslenme bilgisi yine besin seçiminde etkili olarak dolaylı yoldan olsa da toplumun yapısını, ekonomik gücün yanı sıra sağlık harcamalarında büyük kayıplara neden olmakta ve bireylerde sağlık açısından büyük hasarlara sebep olabilmektedir (Şanlıer ve Güler, 2005; Hadaye ve ark., 2019; Alcântara ve ark., 2019).

Toplumların yaşam biçimindeki değişiklikler vücutta meydana gelecek birçok bulaşıcı olmayan hastalıklara yakalanma riskini önemli derecede azalttı̆̆ bilinmekte olup, tüm dünyada olduğu gibi ülkemizde ye- 
tersiz ve dengesiz beslenme neticesinde sağlik açısından ciddi problemlerin ortaya çıkışındaki temel sebeplerden birinin besinsel öğeler hakkında bilgi yetersizliği ile doğru beslenme alışkanlıklarının olmayışını belirtmişlerdir (Şanlier ve ark., 2009).

Gelişen teknolojiyle beraber kitle iletişim araçlarıyla yayılan bilgi kirliliği insanların doğru olmayan besin seçimi ile yanlış beslenme alışkanlıkları kazanmasına sebep olmaktadır. Topluma iletilen ve yanlış öneriler içeren bu bilgi kirliliği insan zihninde karmaşaya yol açarak doğru olmayan beslenme davranışlarına neden olur. Doğru olmayan bu beslenme alışkanlıkları insanlarda başta çağımızın hastalığı obezite olmak üzere kalp, diyabet, hipertansiyon gibi birçok hastalığa sebep olur (Güngör, 2019; Hamulka ve ark., 2018). Bu bağlamda araştırma okullarda görev yapan sınıf öğretmenlerinin beslenme alışkanlıkları ve bilgi düzeylerini belirlemek amacıyla yapılmıştır.

\section{Gereç ve Yöntem}

Araştırmanın evrenini Elazı̆̆ ilinde görev alan sınıf öğretmenleri oluşturmakta olup, örneklemini ise 2018- 2019 yılında Elazığ ilinde görev yapan 200 sınıf öğretmeni oluşturmaktadır. Araştırmada veri toplama tekniklerinden anket yöntemi kullanılmıştır. Verilerin elde edilmesinden " Beslenme Alışkanları Ve Beslenme Bilgi Düzeylerinin İncelenmesi” amaçlayan 25 sorudan oluşan anket uygulanmıştır. Uygulanan anket Yücel (2015) tarafından "Sağlık Çalışanlarının Beslenme Alışkanları ve Beslenme Bilgi Düzeylerinin İncelenmesi" adlı çalışmada, kullanılan anketten istifade edilmiştir. Anket, çalışmanın amacına göre uyarlanmış ve verilerin elde edilmesinde katılımcılara uygulanmıştır.

\section{Çalışma Grubu}

Araştırmanın çalışma grubunu 2018-2019 eğitim öğretim yılında Elazı̆̆ ilinde görev yapan 200 sınıf öğretmeni oluşturmaktadır. 
Tablo.1. Çalışma Grubuna İlişkin Kişisel Bilgiler

\begin{tabular}{llll}
\hline & & Frekans & Yüzde (\%) \\
\hline \multirow{2}{*}{ Cinsiyet } & Kadın & 101 & 50,8 \\
& Erkek & 99 & 49,2 \\
\hline \multirow{4}{*}{ Boy } & $150-160$ & 41 & 20,5 \\
& $161-170$ & 72 & 36,0 \\
& $171-180$ & 66 & 32,5 \\
& $181-$ ve üzeri & 22 & 11,0 \\
\hline \multirow{3}{*}{ Medeni Durum } & Evli & 116 & 58,0 \\
\multirow{2}{*}{ En Son Mezun } & Bekâr & 84 & 42,0 \\
Olunan & Eğitim Yüksek Okulu- & 12 & 6 \\
Okul Türü & Eğitim Enstitüsü & & \\
& Eğitim Fakültesi & 150 & 75 \\
& Diğer Lisans Programı & 38 & 19 \\
\hline \multirow{4}{*}{ Yaş } & $20-30$ & 79 & 39,5 \\
& $31-40$ & 74 & 37,0 \\
& $41-50$ & 39 & 19,5 \\
& $51-60$ & 7 & 3,5 \\
\multirow{4}{*}{ Kilo } & 61 ve üzeri & 1 & 0,5 \\
& $40-50$ & 18 & 9 \\
& $51-60$ & 39 & 19,5 \\
& $61-70$ & 58 & 29 \\
& $71-80$ & 50 & 25 \\
& 80 ve üzeri & 35 & 17,5 \\
\hline
\end{tabular}

Tablo 1 incelendiğinde araştırmaya katılan öğretmenlerin \%50,8'inin kadın, \%49,2'sinin erkek olduğu görülmektedir.

Tablo 1 incelendiğinde araştırmaya katılan öğretmenlerin \%20,5'inin $150-160 \mathrm{~cm}, \% 36,0^{\prime}$ inin $161-170 \mathrm{~cm} \% 32,5^{\prime}$ inin $171-180 \mathrm{~cm}$ ve $\% 11,0^{\prime}$ nin $181 \mathrm{~cm}$ ve üzeri boyda olduğu görülmektedir.

Tablo 1 incelendiğinde araştırmaya katılan öğretmenlerin \%58,0'inin evli; \% 42,0'inin bekar olduğu görülmektedir.

Tablo 1 incelendiğinde araştırmaya katılan öğretmenlerin \%6'sının eğitim yüksekokulu, \%75'inin eğitim fakültesi, \%19'unun da diğer lisans mezunu olduğu görülmektedir.

Tablo 1 incelendiğinde araştırmaya katılan öğretmenlerin \%39,5'inin 20-30, \%37,0'inin 31-40, \%19,5'inin 41-50, \%3,5'inin 51-60 ve \%0,5'inin 61 ve üzeri yaşında olduğu görülmektedir. 
Tablo 1 incelendiğinde araştırmaya katılan öğretmenlerin \%9'unun 4050, \%19,5'unun 51-60, \%29'unun 61-70, \%25'inin 71-80 ve \%17,5'inin 80 ve üzeri kiloda olduğu görülmektedir.

\section{Verilerin Analizi}

Yücel (2015) tarafından geliştirilen anketin uyarlanması sonucunda toplamda 25 madde olan anket formu sınıf öğretmenlerine uygulanmış ve analizleri yapılmıştır. Verilerin analizinde SPSS paket programı kullanılarak, yüzde, frekans testleri uygulanmıştır.

\section{Bulgular ve Yorumlar}

Bu bölümde araştırmaya katılan öğretmenlerin sağlıklı beslenme alışkanlığı ve beslenme bilgi düzeyleri ile ilgili sonuçlarına ilişkin elde edilen bulgular tablolar halinde sunulmuş ve yorumlanmıştır.

Tablo 2. Araştırmaya katılan öğretmenlerin beslenme eğitimine ilişkin sonuçlar

\begin{tabular}{lll}
\hline Soru 7 & F (frekans) & \% (yüzdelik) \\
\hline Evet & 29 & 14,5 \\
Hayir & 171 & 85,5 \\
\hline
\end{tabular}

Araştırmaya katılan öğretmenlerin $\% 14,5$ 'i beslenme eğitimi aldıklarını, \%85,5'i ise beslenme eğitimi almadıklarını belirtmişlerdir.

Tablo 3. Araştırmaya katılan öğretmenlerin kronik hastalı̆̆ına ilişkin sonuçlar

\begin{tabular}{llc}
\hline Soru 8 & F (frekans) & \% (yüzdelik) \\
\hline Hayır, Yok & 168 & 84 \\
Hipertansiyon & 3 & 1,5 \\
Hipertroidi & 2 & 1 \\
Anemi & 6 & 3 \\
Eklem ve kemik hastalıkları & 6 & 3 \\
Hipotroidi & 7 & 3,5 \\
Haşimato & 1 & 0,5 \\
Gastrit, Ülser & 3 & 1,5 \\
Kontipasyon & 4 & 2 \\
\hline
\end{tabular}


Araştırmaya katılan öğretmenlerin \%1,5'i hipertansiyon; \%1'i hipertroidi; \%3'ü anemi; \%3'ü eklem ve kemik hastalıklarl; \%3,5'i hipotroidi; $\% 0,5^{\prime} \mathrm{i}$ haşimato; \%1,5'i gastrit-ülser ve \%2'si kontipasyon kronik hastal1ğına sahip olduklarını belirtmişlerdir. Araştırmaya katılan öğretmenlerin \%84'ü ise hiçbir kronik hastalığının olmadığını ifade etmişlerdir.

Tablo 4. Araştırmaya katılan kullandıkları ilaçlara ilişkin sonuçlar

\begin{tabular}{lcc}
\hline Soru 9 & F (frekans) & \% (yüzdelik) \\
\hline Evet & 23 & 11,5 \\
Hayır & 177 & 88,5 \\
\hline
\end{tabular}

Araştırmaya katılan öğretmenlerin \%11,5'i ilaç kullandığını, $\% 88,5^{\prime}$ inin ise herhangi bir ilaç kullanmadığını ifade etmişlerdir.

Tablo 5. Araştırmaya katılan öğretmenlerin sigara alışkanlığına ilişkin sonuçlar

\begin{tabular}{lcc}
\hline Soru 10 & F (frekans) & \% (yüzdelik) \\
\hline Evet & 55 & 27,5 \\
Hayır & 145 & 72,5 \\
\hline
\end{tabular}

Araştırmaya katılan öğretmenlerin \%27,5'i sigara kullandıklarını, $\% 72,5^{\prime} \mathrm{i}$ ise sigara kullanmadıklarını belirtmişlerdir.

Tablo 6. Araştırmaya katılan öğretmenlerin alkol kullanımına ilişkin sonuçlar

\begin{tabular}{lcc}
\hline Soru 11 & F (frekans) & \% (yüzdelik) \\
\hline Evet & 12 & 6 \\
Hayır & 188 & 94 \\
\hline
\end{tabular}

Araştırmaya katılan öğretmenlerin \%6'sının alkol tükettiğini, \%94'ünün ise alkol tüketmediğini ifade etmişlerdir.

Tablo 7. Araştırmaya katılan öğretmenlerin fiziksel aktivite alışkanlıklarına ilişkin sonuçlar

\begin{tabular}{lcc}
\hline Soru 12 & F (frekans) & \% (yüzdelik) \\
\hline Evet & 64 & 32 \\
Hayır & 136 & 68 \\
\hline
\end{tabular}

Araştırmaya katılan öğretmenlerin \%32'sinin fiziksel aktivite yaptığını; $\% 68$ 'inin ise herhangi bir fiziksel aktivite yapmadığı görülmektedir. 
Tablo 8. Araştırmaya katılan öğretmenlerin ana öğ̈̈n sayısına ilişkin sonuçlar

\begin{tabular}{ccc}
\hline Soru $\mathbf{1 3}$ & F (frekans) & \% (yüzdelik) \\
\hline 1 & 6 & 3 \\
2 & 76 & 38 \\
3 & 99 & 49,5 \\
4 ve üzeri & 19 & 9,5 \\
\hline
\end{tabular}

Araştırmaya katılan öğretmenlerin \%3'ü 1 öğün, \%38'si 2 öğün, \%49,5’i 3 öğün ve \%9,5’i ise 4 ve üzeri öğün tükettiklerini ifade etmişlerdir.

Tablo 9. Araştırmaya katılan öğretmenlerin kahvaltı alışkanlığına ilişkin sonuçlar

\begin{tabular}{lcc}
\hline Soru 14 & F (frekans) & \% (yüzdelik) \\
\hline Evet & 111 & 55,5 \\
Hayır & 89 & 44,5 \\
\hline
\end{tabular}

Araştırmaya katılan öğretmenlerin $\% 55,5$ 'i her gün düzenli kahvaltı yaptıklarını belirtirken, $\% 44,5$ 'i her gün düzenli kahvaltı yapmadıklarını belirtmişlerdir.

Tablo 10. Araştırmaya katılan öğretmenlerin gün içerisinde öğün atlamaya ilişkin sonuçlar

\begin{tabular}{lcc}
\hline Soru 15 & F (frekans) & \% (yüzdelik) \\
\hline Evet & 86 & 43 \\
Hayir & 44 & 22 \\
Bazen & 70 & 35 \\
\hline
\end{tabular}

Araştırmaya katılan öğretmenlerin \%43'ü gün içerisinde öğün atladıklarını; \%22'si gün içerisinde öğün atlamadıklarını; \%35'i ise bazen gün içerisinde öğün atladığını ifade etmiştir.

Tablo 11. Araştırmaya katılan öğretmenlerin en sık atladıkları öğüne ilişkin sonuçlar

\begin{tabular}{lcc}
\hline Soru 16 & F (frekans) & \% (yüzdelik) \\
\hline Atlamam & 49 & 24,5 \\
Kahvaltı & 59 & 29,5 \\
Öğle & 85 & 42,5 \\
Akşam & 7 & 3,5 \\
\hline
\end{tabular}


Araştırmaya katılan öğretmenlerin \%29,5'i kahvaltı öğününü atladığını, \%42,5'ini öğle ögününü atladığını, \%3,5'i akşam öğününü atladıklarını belirtirken, \%24,5'i ise gün içerisinde hiç ögün atlamadıklarını belirtmişlerdir.

Tablo 12. Araştırmaya katılan öğretmenlerin öğ̈̈n atlama nedenlerine ilişkin sonuçlar

\begin{tabular}{lll}
\hline Soru $\mathbf{1 7}$ & F (frekans) & \% (yüzdelik) \\
\hline Atlamam & 33 & 16,5 \\
Unuttuğum için & 6 & 3 \\
Canım istemediği için & 38 & 19 \\
Alışkanlığım yok & 25 & 12,5 \\
Fırsat bulamadığım için & 81 & 40,5 \\
Zayıflamak için & 6 & 3 \\
Diğer & 11 & 5,5 \\
\hline
\end{tabular}

Araştırmaya katılan öğretmenlerin \%3'ü unuttukları için gün içerisinde öğün atladığını, \%19'u gün içerisinde canları istemedikleri için, \%12,5'i öğün alışkanlıkları olmadığ 1 için, \%40,5'i gün içerisinde fırsat bulamadıkları için öğün atladığını, \% 3'ü zayıflamak için öğün atladığını, $\% 5,5$ ' i ise diğer sebeplerden ötürü öğün atladığını ifade etmişlerdir. Araştırmaya katılan öğretmenlerin \%16,5'i ise gün içerisinde öğün atlamadıklarını belirtmişlerdir.

Tablo 13. Araştırmaya katılan öğretmenlerin günlük ara öğün sayısına ilişkin sonuçlar

\begin{tabular}{ccc}
\hline Soru $\mathbf{1 8}$ & F (frekans) & \% (yüzdelik) \\
\hline Hiç & 64 & 32 \\
1 & 78 & 39 \\
2 & 51 & 5,5 \\
3 ve daha fazla & 7 & 3,5 \\
\hline
\end{tabular}

Araştırmaya katılan öğretmenlerin \%39'u günde bir ara öğün, \% 25,5'i günde iki ara öğün, \%3,5'i ise üç ve daha fazla ara öğün tükettiklerini belirtirken, \%32'si hiç ara öğün tüketmediklerini ifade etmişlerdir. 
Tablo 14. Araştırmaya katılan öğretmenlerin öğün aralarında tükettikleri yiyecekiçecek türüne ilişkin sonuçlar

\begin{tabular}{lcc}
\hline Soru 19 & F (frekans) & \% (yüzdelik) \\
\hline Asitli- Gazlı içecekler & 42 & 21 \\
Kek/Kurabiyeler & 38 & 19 \\
Bisküvi & & \\
Meyve/Kuru meyve & 33 & 16,5 \\
Diğer & 60 & 30 \\
Meyve Suyu & 6 & 3 \\
Şeker/Çikolata & 10 & 5 \\
Kuruyemiş & 11 & 5,5 \\
\hline
\end{tabular}

Araştırmaya katılan öğretmenlerin \%21'i asitli- gazlı içecekler, \%19'u kek-kurabiye-bisküvi, \%16,5'i meyve-kuru meyve, \%3'ü meyve suyu, \%5'i şeker-çikolata, \% 5,5'i kuruyemiş ve \%30'u ise diğer yiyecek ve içecek türlerini tükettikleri görülmektedir.

Tablo 15. Araştırmaya katılan öğretmenlerin günlük su tüketimlerine ilişkin sonuçlar

\begin{tabular}{lcc}
\hline Soru 20 & F (frekans) & \% (yüzdelik) \\
\hline 2 Litre ve altı & 160 & 80 \\
2,5 Litre & 22 & 11 \\
3 Litre ve üzeri & 18 & 9 \\
\hline
\end{tabular}

Araştırmaya katılan öğretmenlerin \%80'si günde 2 litre ve altı, $\% 11$ 'inin günde 2,5 litre, $\% 9^{\prime}$ unun ise günde 3 litre ve üzeri su tükettikleri görülmektedir.

Tablo 16. Araştırmaya katılan öğretmenlerin günlük çay-kahve tüketimlerine ilişkin sonuçlar

\begin{tabular}{lcc}
\hline Soru 21 & F (frekans) & \% (yüzdelik) \\
\hline 5 ve altı & 122 & 61 \\
$6-10$ & 54 & 27 \\
11 ve üzeri & 24 & 12 \\
\hline
\end{tabular}

Araştırmaya katılan öğretmenler \%61'i günde 5 bardak ve altı, \%27'si günde 6-10 bardak arası, \%12'si ise günde 11 bardak ve üzeri çay-kahve tükettiklerini ifade etmişlerdir. 
Tablo 17. Araştırmaya katılan öğretmenlerin yemeklerdeki tuz tercihine ilişkin sonuçlar

\begin{tabular}{lll}
\hline Soru 22 & F (frekans) & \% (yüzdelik) \\
\hline Tuzsuz & 13 & 6,5 \\
Az tuzlu & 88 & 44 \\
Orta tuzlu & 21 & 10,5 \\
Çok tuzlu & 78 & 39 \\
\hline
\end{tabular}

Araştırmaya katılan öğretmenler yemeklerini \%6,5'i tuzsuz, \%39'u az tuzlu, \%44'ü orta tuzlu, \%10,5' i ise çok tuzlu tükettiklerini belirtmiştir.

Tablo 18. Araştırmaya katılan öğretmenlerin yemek yeme hızlarına ilişkin sonuçlar

\begin{tabular}{lll}
\hline Soru 23 & F (frekans) & \% (yüzdelik) \\
\hline Hizlı & 40 & 20 \\
Normal hızda & 105 & 52,5 \\
Yavaş & 47 & 23,5 \\
Çok yavaş & 8 & 4 \\
\hline
\end{tabular}

Araştırmaya katılan öğretmenler \%20'si yemekleri hızlı, \%52,5'i yemekleri normal hızda \%23,5'i yemekleri yavaş, \%4'ü ise yemekleri çok yavaş yediklerini belirtmektedirler.

Tablo 19. Araştırmaya katılan öğretmenlerin Üzüntülü-Yorgun olduklarında yemek tüketim durumlarına ilişkin sonuçlar

\begin{tabular}{lcc}
\hline Soru 24 & F (frekans) & \% (yüzdelik) \\
\hline Hiç yemek yemem & 47 & 23,5 \\
Her zamankinden az yerim & 80 & 40 \\
Her zamankinden çok ve sık yerim & 33 & 16,5 \\
Bir değişiklik olmaz & 40 & 20 \\
\hline
\end{tabular}

Araştırmaya katılan öğretmenler üzüntülü-yorgun olduklarında $\% 23,5$ 'i hiç yemek yemediğini, $\% 40$ '1 her zamankinden çok yediğini, $\% 16,5^{\prime}$ i her zamankinden çok ve sık yemek yediğini ve \%20'si ise yemek tüketiminde bir değişiklik olmadığını ifade etmiştir. 
Tablo 20. Araştırmaya katılan öğretmenlerin sevinçli-heyecanlı olduklarında yemek tüketim durumlarna ilişkin sonuçlar

\begin{tabular}{lcc}
\hline Soru 25 & F (frekans) & \% (yüzdelik) \\
\hline Hiç yemek yemem & 21 & 10,5 \\
Her zamankinden az yerim & 44 & 22 \\
Her zamankinden çok ve sık yerim & 46 & 23 \\
Bir değişiklik olmaz & 89 & 44,5 \\
\hline
\end{tabular}

Araştırmaya katılan öğretmenler sevinçli-heyecanlı olduklarında $\% 10,5$ 'i hiç yemek yemediğini, \%22'si her zamankinden çok yemek yediğini, \%23‘ü her zamankinden çok ve sık yemek yediğini ve $\% 44,5$ 'i ise yemek yeme düzeyinde bir değişiklik olmadığını ifade etmişlerdir.

\section{Tartışma, Sonuç ve Öneriler}

Araştırmaya katılan öğretmenlerin büyük çoğunluğu beslenme eğitimi almadıklarını ifade etmişlerdir. Kayapınar (2011) İlköğretim öğretmenlerinin beslenme alışkanlıkları ve bilgi düzeylerini incelediği araştırmada öğretmenlerin beslenme bilgi düzeylerin yetersiz olduğunu belirtmiştir. Çongar ve Özdemir (2004) Sivas il merkezinde görev yapan beden eğitimi öğretmenlerinin genel beslenme ve sporcu beslenmesi ile ilgili bilgi düzeylerini araştırdığı çalışmada öğretmenlerin beslenme bilgi düzeylerinin yetersiz olduğunu tespit etmişlerdir. El-Ahmady ve El-Wakeel (2017) ise yapmış olduğu çalışmada kız öğrencilerin erkek öğrencilerden beslenme bilgi düzeyleri ve alışkanlıklarının yüksek olduğunu belirtmişlerdir. Metos ve ark., (2019) yaptığı çalışmada katılımcıların beslenme bilgi düzeylerinin düşük olduğunu ifade etmişlerdir.

Araştırmaya katılan öğretmenlerin büyük çoğunluğu herhangi bir kronik hastalıklarının olmadığını ve ilaç kullanmadıklarını ifade etmişlerdir. Yardımcı ve ark., (2018) öğretmenlerin sağlık inanışları ve diyet suplemanı kullanma durumunu incelediği çalışmada öğretmenlerin büyük bir kısmının herhangi bir kronik hastalığının bulunmadığını tespit etmişlerdir. Bayramoğlu ve ark., (2018) akademisyenlerin beslenme alışkanlıklarını araştırdığı çalışmada akademisyenlerin büyük bir kısmının herhangi bir kronik hastalığının olmadığını ifade etmişlerdir. 
Araştırmaya katılan öğretmenlerin büyük çoğunluğu alkol ve sigara tüketmediğini ve düzenli fiziksel aktivite yapmadıklarını ifade etmişlerdir. Güleç ve ark., (2008) kız yurdunda kalan öğrencilerin beslenme alışkanlarını incelediği araştırmada yurtta kalan öğrencilerin büyük bir kısmının alkol ve sigara içmediklerini tespit etmişlerdir. Araştırmaya katılan öğretmenlerin büyük çoğunluğu düzenli olarak üç öğün beslendiklerini ve düzenli olarak kahvaltı yaptıklarını belirtmişlerdir. Sözen ve ark., (2009) metal sektöründe çalışanlar üzerine yaptığı araştırmada büyük bir kısmının hiç alkol ve sigara kullanmadığını yada sonradan bıraktığını tespit etmişlerdir.

Araştırmaya katılan öğretmenlerin yarısına yakını gün içerisinde öğün atladıklarını, en çok atlanan öğünün ise öğle yemeği olduğunu ve bunun da yoğunluktan kaynaklandığını ifade etmişlerdir. Özyazıcıŏ̆lu ve ark., (2009) yaptıkları çalışmada katılımcıların en fazla atladıkları öğünün kahvaltı ve öğle yemeği olduğunu bildirmişlerdir. Zemzemoğlu ve ark., (2019) sağlık bilimleri fakültesi öğrencilerinin beslenme alışkanlıklarının belirlenmesini incelediği araştırmada öğrencilerin en fazla atladıkları öğünün öğle yemeği olduğunu bildirmişlerdir. Bayramoğlu ve ark., (2018) Kadın akademisyenlerin beslenme alışkanlıklarını incelediği çalışmada en fazla atladıkları ögünün öğle yemeği olduğu öğün atlama sebebi olarak da fırsat bulama olduğunu ifade etmiştirler.

Araştırmaya katılan öğretmenler asitli-gazlı içecekler, günde 5 bardak ve altı çay kahve ve günde 2 litreden az su tükettiklerini ifade etmişlerdir. Orak ve ark., (2006) Süleyman Demirel Üniversitesi öğrencilerinin beslenme alışkanlıklarının araştırılması incelediği çalışmada öğrencilerin büyük çoğunluğun çay-kahve tükettiklerini belirtmişlerdir. Saygın ve ark., (2011) üniversite öğrencileri üzerine yaptıkları araştırmada öğrencilerin büyük bir kısmının asitli-gazlı içecek tükettiklerini ifade etmişlerdir. Irwin ve ark., (2019) yaptığı çalışmada katılımcıların en çok su tükettiklerini ifade etmiştirler.

Araştırmaya katılan öğretmenlerin büyük çoğunluğu yemeklerini normal hızda yediklerini ve tuz tüketiminin orta düzeyde olduğunu ifade etmişlerdir. Öner ve ark., (2013) yaptığ1 çalışmada büyük bir kısmının günlük tuz tüketim düzeyinin Dünya Sağlık Örgütü'nün önerisinden (günlük 5 gr ve altında) yüksek olduğunu ifade etmiştirler. Ulaş ve ark., (2013) 
yaptığı çalışmada sağlık yüksekokulu öğrencilerinin büyük bir kısmının normal hızda yemek yediklerini tespit etmiştir.

Araştırmaya katılan öğretmenler üzüntülü-yorgun olduklarında yemekleri her zamankinden çok yediğini ve sevinçli- heyecanlı olduklarında ise yemek yeme düzeyinde herhangi bir değişiklik olmadığını belirtmişlerdir. Yücel (2015) yaptığı çalışmada katılımcların üzüntülü ve yorgun olduğunda büyük çoğunluğunun az yada daha çok yemek yediğini, sevinçli ve heyecanlı olduğunda ise yemek yeme alışkanlığında herhangi bir değişiklik olmadığını belirtmiştir. Özçelik (2000) yaptığı çalışmada katılımcıların üzüntülü-yorgun iken daha az yemek yediğini, sevinçli-heyecanlı iken herhangi bir değiş̧iklik olmadığın ifade etmiştir. Çetin ve Sarper (2013) yaptıkları araştırmada katılımcıların büyük bir kısmının üzüntülü ve yorgun olduklarında hiç yemek yemediklerini, sevinçli-heyecanlı olduklarında ise daha fazla yemek yediklerini bildirmişlerdir.

\section{Öneriler}

- Öğretmenlere beslenme eğitimi verilmelidir.

- Öğretmenlerin gazlı içecek tüketimini azaltacak çalışmalar yapılabilir.

- Öğretmenlerin su tüketiminin önemini kavraması için gerekli çalışmalar yapilmalıdır.

- Beslenme sırasında öğün atlamanın beslenme alışkanlığını olumsuz etkileyeceğini belirtecek çalışmalar yapılmalıdır.

- Araştırmacılar öğretmenlerin beslenme alışkanlığı hususunda bildiği yanlış bilgileri araştırabilirler.

- Araştırmacılar öğretmenlerin beslenme alışkanlığı hakkında öğrencilerine verdikleri bilgileri ölçecek çalışmalar yapabilirler.

- Araştırmacılar öğretmenlerin fiziksel aktivite düzeylerini ölçecek çalışmalar yapabilirler. 


\title{
EXTENDED ABSTRACT
}

\section{Investigation of the Nutritional Habits of Classroom Teachers}

\author{
* \\ Eyüp Bozkurt - Ramazan Erdoğan \\ Firat University-Provincial Directorate of Youth and Sports
}

With the changing way of life, the nutritional habits of people also change and it leans towards the nutritional habits that are called unhealthy nutrition. People now eat in a short time by consuming rapidly and they prefer foods such as fast foods more. When all these changes are combined with the developments in the field of technology, most people now eat either while they are on their computers or while they have their phones in their hands. This change undoubtedly brings many diseases and problems along. These problems emerge in many subjects such as obesity and chronic diseases. The increase in these diseases reduces our quality of life and cause unhealthy generations to emerge. People now complain from many diseases and start to pursue the subject of a healthy life. As a result of the disease problems emerging recently, many concepts such as organic food and natural food have started to take part in our lives. At the same time, people now need features such as nutrition advisor and healthy life advisor. While dealing with these problems, if we try to correct the mistakes not only as just an individual but as a society, we carry out a more permanent and effective fight. In order to avoid these problems as a society, all units need to act together and within a common framework. One of the most important duties in this fight falls on the shoulders of schools and teachers. Considering the age group especially the classroom teachers address, we can state that the largest duty falls on the shoulders of classroom teachers.

Classroom teachers are the authority whom the children, who leave the family environment at an early age and enter into a social environment, meet the first. Therefore, children excessively connect with their teachers and regard them as role models. Children observe all the behavior the teachers do or do not in the school and do these themselves. Thus, classroom 
teachers have a significant place. When teachers have sufficient knowledge about healthy life and transfer this to children, they provide a significant contribution to children's lives. Furthermore, an effective education period is provided. Considering all these effects, it is an important point that teachers should have knowledge about healthy life and practice these in their lives. When teachers have enough knowledge about healthy life, they do not only contribute to the regulation of their own lives but also to the lives of students and families. It will be easy and effective for a teacher with healthy life system to raise individuals with healthy life knowledge.

\section{Aim of the Study}

The aim of this study is to determine the nutritional habits and knowledge levels of classroom teachers who serve in schools. This is because the nutritional habits and knowledge of classroom teachers will affect the children for whom they are role models and they have an effect that can guide the children. Several knowledge levels are of significance in terms of the nutritional habits of classroom teachers. For this purpose, analyses were conducted by taking teachers' opinions and evaluations were conducted.

\section{Material and Method}

The population of the study consists of classroom teachers who serve in the city of Elazığ. The sample of the study consists of 200 classroom teachers who served in the city of Elazı $\breve{g}$ during the 2018-2019 period. In the study, the survey method, which is a data collection method, was used. In the data collection, a questionnaire with 25 items that aim to "Investigate nutritional habits and Nutritional Knowledge Level" was conducted. The study titled "Investigation of Nutritional Habits and Nutritional Knowledge Levels of Healthcare Workers" by Yücel (2015) was utilized in the questionnaire conducted. The questionnaire was adapted according to the aims of the study and conducted with the participants for the data collection. The study is of quantitative design and the surveying method, consistent with the nature of the study, was used. 


\section{Data Analysis}

As a result of the adaptation of the questionnaire developed by Yücel (2015), the questionnaire form with a total of 25 items was conducted with classroom teachers and the analyses were conducted. In the analysis of the data, SPSS package software was used and percentage and frequency tests were conducted.

\section{Findings and Conclusions}

A majority of the participating teachers in the study stated that they did not receive a nutritional education.

A majority of the participating teachers in the study stated that they did not have any chronical disease and did not use any medication.

A majority of the participating teachers stated that they did not consume alcohol or smoke cigarettes and they did not do physical exercises regularly.

Almost half of the participating teachers in the study stated that they skipped meals within the day and the meal that was skipped the most was the lunch, further stating that this was due to busyness.

The participating teachers in the study stated that they consumed 5 glasses or lower tea and coffee daily and drank less than two liters of water in a day.

A majority of the participating teachers stated that they ate their food at a normal pace and their salt consumption was at a moderate level.

The participating teachers in the study stated that they eat more than usual when they are sad or tired while they stated that there is no difference in their eating order when they are happy or excited.

A majority of the participating teachers stated that they regularly had three meals and they have breakfast regularly.

Considering all these findings, it can be stated that classroom teachers need nutritional education and obtain healthy nutritional habits, thus, enabling them to guide the children by information them. Furthermore, teachers should also have knowledge about the damages of skipping meals, consuming carbonated beverages and low water consumption in terms of their health. A healthy life is a concept that concerns and affects 
all parts of society. Teachers will especially provide significant contributions to correct wrong habits by having knowledge about healthy life and transferring this knowledge to students.

\section{Kaynakça / References}

Alcântara C. M., Silva A. N. S., Pinheiro P. N. D. C. ve Queiroz M. V. O. (2019). Digital technologies for promotion of healthy eating habits in teenagers. Revista Brasileira de Enfermagem, 72(2) 513-520.

Bayramoğlu, A., Ceceloğlu, D., Cirit, H. ve Abasız, N. (2018). Artvin Çoruh Üniversitesindeki kadın akademisyenlerin beslenme alışkanlıkları. Osmangazi Tip Dergisi, 41(3), 235-242 Doi: 10.20515/otd.-453211

Çetin, G., ve Sarper, F. (2013). Tip fakültesi birinci ve son sinıfa devam eden öğrencilerin beslenme bilgi ve alışkanlıkları üzerine bir araştırma. 21. Yüzyılda Ĕ̆itim Ve Toplum Eğitim Bilimleri Ve Sosyal Araştırmalar Dergisi, 2(6), 84-104.

Demirezen, E. ve Coşansu, G. (2005). Adölesan çağı öğrencilerde beslenme alışkanlıklarının değerlendirilmesi. Sürekli Tip Eğitimi Dergisi, 14(8),174-178.

Di Daniele, N. (2019). The role of preventive nutrition in chronic non-communicable diseases. Nutrients, 11(5),1074.

El-Ahmady, S. ve El-Wakeel, L. (2017). The effects of nutrition awareness and knowledge on health habits and performance among pharmacy students in Egypt. Journal Of Community Health, 42(2), 213-220.

Güleç, M., Yabancı, N., Göçgeldi, E. ve Bakır, B. (2008). Ankara'da iki kız öğrenci yurdunda kalan öğrencilerin beslenme alışkanlıkları. Gülhane Tip Dergisi, 50(2),102-109.

Güngör, E.Ö. (2019). Sağllklı beslenmede bireysel ve grup eğitiminin bireylerin beslenme alışkanlıkları ve besin seçimi üzerine etkisi. Doktora Tezi, Başkent Üniversitesi, Sağlık Bilimleri Enstitüsü, Beslenme ve Diyetetik Anabilim Dall, Ankara.

Hadaye, R., Pathak, B. ve Lavangare, S. (2019). Nutritional status of the student nurses of a tertiary health-care center - a mixed-method study. Journal of Family Medicine and Primary Care, 8(3),1028-1034. 
Hamulka, J., Wadolowska, L., Hoffmann, M., Kowalkowska, J. ve Gutkowska, K. (2018). Effect of an education program on nutrition knowledge, attitudes toward nutrition, diet quality, lifestyle, and body composition in polish teenagers. the abc of healthy eating project: Design, protocol, and methodology. Nutrients, 10(10), 1439.

Irwin, B. R., Speechley, M. R. ve Gilliland, J. A. (2019). Assessing the relationship between water and nutrition knowledge and beverage consumption habits in children. Public Health Nutrition, 1-14, 22(9), https://doi.org/10.1017/S1368980019000715

Kayapınar, F. Ç. (2011). Kadın ve erkek ilköğretim öğretmenlerinin beslenme alışkanlıkları ve bilgi düzeylerinin karşılaştırılması. Türkiye Klinikleri Spor Bilimleri, 3(1), 8-15.

Küçük U. (2019). Paramedik Öğrencilerinin Beslenme Durumları Ve Etkileyen Faktörler. Adnan Menderes Üniversitesi Să̆lık Bilimleri Fakültesi Dergisi, 3(1), 1-10.

Merdol, T.K. (2008). Beslenme eğitimi ve danışmanlı̆̆ı. Sağlık Bakanlığı Yayın No: 726, Ankara: Klasmat Matbaacilik.

Metos, J. M., Sarnoff, K. ve Jordan, K. C. (2019). Teachers' perceived and desired roles in nutrition education. Journal of School Health, 89(1), 68-76.

Mukudi, E. (2003). Nutrition status, education participation, and school achievement among Kenyan middle-school children. Nutrition, 19(7-8), 612-616.

Öner, C., Çatak, B., Yıldız, M., Erdoğan, A., Canpolat, İ. ve Seğmen, Ö. (2013). Kantin çalışanlarının besin güvenliği hakkındaki tutum ve davranışları. Bozok Tip Dergisi, 1, 21-25.

Özçelik, A. Ö. (2000). Sağlık personelinin beslenme alışkanlıkları üzerinde bir araştırma. The Journal of Food, 25(2), 93-99.

Özyazıcıoğlu, N., Çınar, H. G., Buran, G. ve Ayverdi, D. (2009). Uludağ Üniversitesi sağlık yüksekokulu öğrencilerinin beslenme alışkanlıkları. Anadolu Hemşirelik ve Sağlık Bilimleri Dergisi, 12(2), 34-40.

Sabbağ, Ç. ve Sürücüoğlu, M.S. (2011). İlköğretim öğrencilerine verilen beslenme eğitiminin beslenme tutum ve davranışlarına etkisinin değerlendirilmesi. Gida Teknolojileri Elektronik Dergisi, 6(3),1-13.

Saygın, M., Öngel, K., Çalışkan, S., Yağlı, M. A., Has, M., Gonca, T. ve Kurt, Y. (2011). Süleyman Demirel Üniversitesi öğrencilerinin beslenme alışkanlıkları. Süleyman Demirel Üniversitesi Tıp Fakültesi Dergisi, 18(2),43-47. 
Sözen, S., Bilir, N., Yıldız, A. N., Yıldız, E. ve Sözen, T. (2009). Metal sektöründe bir işyerinde çalışanların beslenme alışkanlıkları ve ilişkili antropometrik ölçümleri. Toplum Hekimliği Bülteni, 28(3), 7-14.

Şanlıer, N. ve Güler, A. (2005). İlköğretim ikinci kademesinde eğitim gören öğrencilere verilen beslenme eğitiminin öğrencilerin beslenme bilgi düzeyi ve alışkanlıklarına etkisi. Beslenme ve Diyet Dergisi, 32(2),31-38.

Şanlıer, N., Konaklığlu, E. ve Güçer, E. (2009). Gençlerin beslenme bilgi, alışkanlık ve davranışları ile beden kütle indeksleri arasındaki ilişki. Gü, Gazi Eğitim Fakültesi Dergisi, 29(2), 333-352.

T.C Sağlık Bakanlığı Türkiye Halk Sağlığı Kurumu (2016). Sağllklı beslenme ve fiziksel aktivite öğretmen el kitabı. Ankara: T.C Sağlık Bakanlığı Türkiye Halk Sağlığı Kurumu

Yücel, B. (2015). Sağllk çalışanlarının beslenme alışkanları ve beslenme bilgi düzeylerinin incelenmesi. Yüksek Lisans Tezi, Başkent Üniversitesi Sağlık Bilimleri Enstitüsü, Beslenme ve Diyetetik Bölümü, Ankara.

Orak, S., Akgün, S. ve Orhan, H. (2006). Süleyman Demirel Üniversitesi öğrencilerinin beslenme alışkanlıklarının araştırılması. SDÜ Tıp Fakültesi Dergisi, 13(2), 5-11.

Zemzemoğlu, T.E.A., Erem, S., Uludağ, E. ve Uzun, S. (2019). Sağlık Bilimleri fakültesi öğrencilerinin beslenme alışkanlıklarının belirlenmesi. Food And Health, 5(3), 185-196.

\section{Kaynakça Bilgisi / Citation Information}

Bozkurt, E. ve Erdoğan, R. (2019). Sınıf öğretmenlerinin beslenme alışkanlıklarının incelenmesi. OPUS - Uluslararası Toplum Araştırmaları Dergisi, 13(19), 75-94. DOI: 10.26466/opus.573261 